\title{
Photoperiod influences the annual reproductive cycle of the male pallid bat (Antrozous pallidus)
}

\author{
Laura J. Beasley and I. Zucker \\ Department of Psychology, University of California, Berkeley, California 94720, U.S.A.
}

\begin{abstract}
Summary. Adult pallids bats collected in April or May, were maintained in short or long photoperiods ( 10 or $14 \mathrm{~h}$ light/day) for 3-6 months. In August, the short-day bats had regressed testes, epididymal spermatozoa and fully developed accessory sex glands, corresponding to the autumnal reproductive condition of field animals; long-day bats had testes undergoing spermatogenesis, few epididymal spermatozoa and undeveloped accessory sex glands (summer reproductive condition). Bat's in each photoperiod manifested the expected autumnal reproductive pattern in October. We suggest that photoperiod influences the reproductive physiology of male pallid bats by affecting an endogenous circannual reproductive rhythm.
\end{abstract}

\section{Introduction}

During the breeding season, the testes of most mammals undergo active spermatogenesis. High levels of gonadotrophins and androgens stimulate spermatogenesis, secretory activity of the accessory glands and copulatory behaviour; at the end of the breeding season, the testes are regressed and the accessory glands involuted (Sadleir, 1969; Lincoln, 1981). Male bats of several vespertilionid species are exceptional in that the testes are regressed and aspermatic at the time of mating. Spermatogenesis occurs during the summer when males are incapable of inseminating females; during this time the epididymides are devoid of spermatozoa and the accessory sex glands are non-secretory. Mating occurs in the autumn, by which time the testes have regressed, the epididymides are full of spermatozoa and the accessory glands large and active (Wimsatt, 1969; Gustafson, 1979). This reproductive pattern is uncommon among mammals, but similar cycles have been described in non-mammalian vertebrates (Licht, 1984).

The proximate factors underlying seasonal breeding cycles of vespertilionid bats remain to be specified. The annual fluctuation in daylength is the primary cue for phasing reproductive activity in many animals. In several rodents reproduction is stimulated by long daylengths and inhibited by short days (Reiter, 1980; Zucker, Johnston \& Frost, 1980). Conversely, some ungulates breed in the autumn and reproduction is initiated by short photoperiods and inhibited by long daylengths (Legan \& Winans, 1981). Only one study has examined the influence of photoperiod on reproduction of bats; reproductive tissue weight did not differ in pipistrelle bats (Pipistrellus pipistrellus) maintained in long or short days (Racey, 1978). In bats, "there is no clear experimental evidence that photoperiod is involved in the timing of gametogenesis" (Racey, 1982, p. 93).

The present experiments examined the influence of photoperiod on gametogenesis of adult male pallid bats. We tested the hypothesis that, as in temperate-zone rodents, long daylengths stimulate development of the testes or that short daylengths induce testicular regression. Since the testicular and epididymal cycles are out of phase in this species, the role of photoperiod in the regulation of each of these rhythms was analysed separately. Assessment of the reproductive 
physiology of adult male pallid bats has previously been limited to observation of external morphology (Herreid, 1961). Consequently, tissues from several adult males recently collected from the field were examined to characterize more precisely the seasonal reproductive cycle.

\section{Materials and Methods}

Experiment 1. Eleven adult male pallid bats (Antrozous pallidus) collected from the Napa Valley, California during 7 months of the year (April-October) were autopsied within 3 days of capture. The testes, epididymides and accessory glands were weighed and prepared for histological examination.

Experiment 2. Fifty-one adult male bats ( $\geqslant 11$ months of age), collected in the Napa Valley between mid-A pril and early May during 3 years (1980-1982), were maintained in long (14L :10D; $14 \mathrm{~h} \mathrm{light/day)}$ or short ( $10 \mathrm{~L}: 14 \mathrm{D})$ days. Bats were housed in groups in stainless-steel cages $(34 \times 44$ $\times 17 \mathrm{~cm}$ ) at $23 \pm 2^{\circ} \mathrm{C}$ and fed $4 \mathrm{~g}$ mealworms (larvae of Tenebrio molitor) each per day.

To assess changes in testicular size externally, scrotal sac dimensions (midline width measured with callipers and height estimated as high or low) were determined monthly. Bats were of comparable body weight and external reproductive condition at the start of the experiment during each of the 3 years. Bats were killed at 11-12 weeks (14-16 July), 16-18 weeks (15-19 August), 2123 weeks (22-23 September) or 26-28 weeks (27-29 October) after collection.

Autopsy. Bats were killed with an overdose of pentobarbitone sodium. Reproductive tissues (testes, epididymides and the accessory gland complex) were dissected, measured, weighed and prepared for histological examination. The accessory gland complex included the prostate, ampullary glands and coagulating glands. Tissues were fixed with Bouin's solution or buffered formalin, embedded in paraffin wax, sectioned at $5 \mu \mathrm{m}$ and stained with haematoxylin and eosin. Histological rating was based on the combined activity of the testes and epididymides as follows: 1 testes containing primary and/or secondary spermatocytes and the epididymides devoid of spermatozoa; 2-testes manifesting all stages of spermatogenesis but few spermatozoa in the testes and/or epididymides; 3 -testes containing spermatids and/or spermatozoa and the epididymides full of spermatozoa; 4 -testes having a regressed appearance, containing only Sertoli cells and a few spermatogonia and the epididymides containing many spermatozoa.

Statistical analysis. To determine whether size of the scrotal sac is indicative of reproductive condition, correlation coefficients were calculated between reproductive measures assessed at autopsy and scrotal measurements (corrected scrotal width $=$ scrotal width in mm, multiplied by 1 or 1.5 depending on whether scrotal height was low or high). An analysis of variance for independent samples was performed for each measure and planned comparisons ( $t$ tests) were used to assess the influence of photoperiod during August, September and October. Individual changes in corrected scrotal width were assessed with a repeated measures analysis of variance and dependent $t$ tests. Too few animals were sampled in July to permit statistical analysis; results for these animals are included for descriptive purposes only.

\section{Results}

\section{Experiment $1:$ samples collected in the field}

Testicular weights were low between April and July, high in August and September and low again in October (Text-fig. 1a). The epididymides were relatively light between April and August and were heavy during September and October (Text-fig. 1b). The weights of the accessory gland complex parallel the changes in epididymal weight (Text-fig. lc) except that the value was higher in 


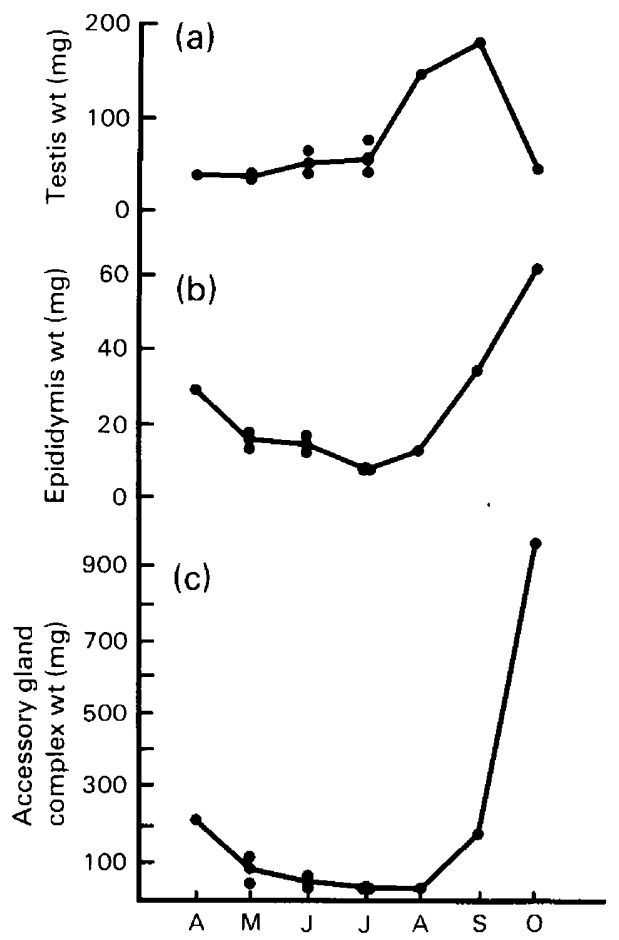

Text-fig. 1. Absolute weights of testes, epididymides and accessory gland complex of adult male pallid bats autopsied within 3 days of capture.

April than in succeeding months. During April, May and October, the animals had regressed testes and epididymal spermatozoa. Between June and August, all bats had testes with primary and/or secondary spermatocytes and epididymides devoid of spermatozoa. The animal collected in September had spermatozoa in the testes and epididymides.

\section{Experiment 2: captive bats}

Scrotal sac. Corrected scrotal width was positively correlated with testis weight $(r=0 \cdot 52, P<$ 0.0001). Photoperiod did not affect corrected scrotal width (Text-fig. 2). In each animal, corrected scrotal width increased to peak values during the summer and decreased in September; peak summer values in each photoperiod were greater than those recorded in May or September $(P<0.002)$.

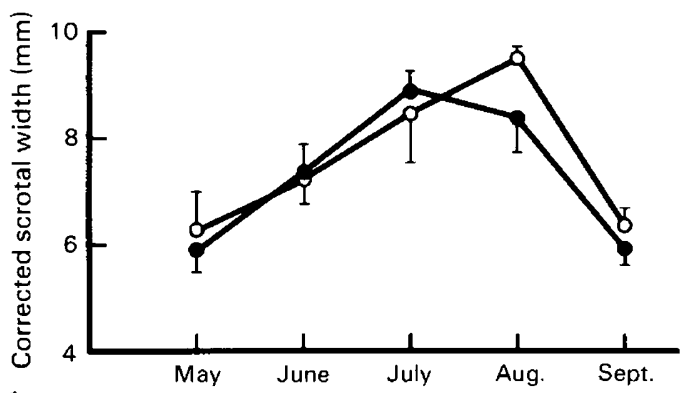

Text-fig. 2. Corrected scrotal width $(\mathrm{mm})$ of 10 long-day $(O)$ and 9 short-day $(O)$ pallid bats examined between May and September. Values are mean \pm s.e.m. 
Testis weight. Long-day and short-day bats differed only during August; absolute testis weights were greater in long-day than short-day animals $(P<0.025$; Text-fig. 3a). Relative testis weight (mg/g body weight) and testis width (not illustrated) were also greater in long-day than in short-day bats during August $(P<0.03$ and $P<0.05$ respectively). In long-day bats, testes weighed less in September or October than in August (Text-fig. 3a; $P<0.0001$ ), whereas in short-day bats, testis weight did not differ between August and October.

For all bats, testis weight was negatively correlated with epididymal weight $(r=-0 \cdot 31, P<$ $0.01)$, accessory gland complex weight $(r=-0.57, P<0.0001)$ and histological rating $(r=-0.56$, $P<0.0001$ ).

Epididymis weight. Photoperiod did not influence epididymal weight during any month $(P>$ 0.05 ; Text-fig. 3b). Epididymides were heavier in September or October than in August for shortday $(P<0.02)$ and long-day $(P<0.04)$ bats.

Accessory gland complex. In August, the accessory gland complex was much heavier in short-day than in long-day animals ( $P<0.001$; Text-fig. 3c). In the long-day animals, the accessory gland complex was heavier during September or October than in August $(P<0.0001)$; the weight of the accessory gland complex did not differ between August and Ocober in the short-day animals.

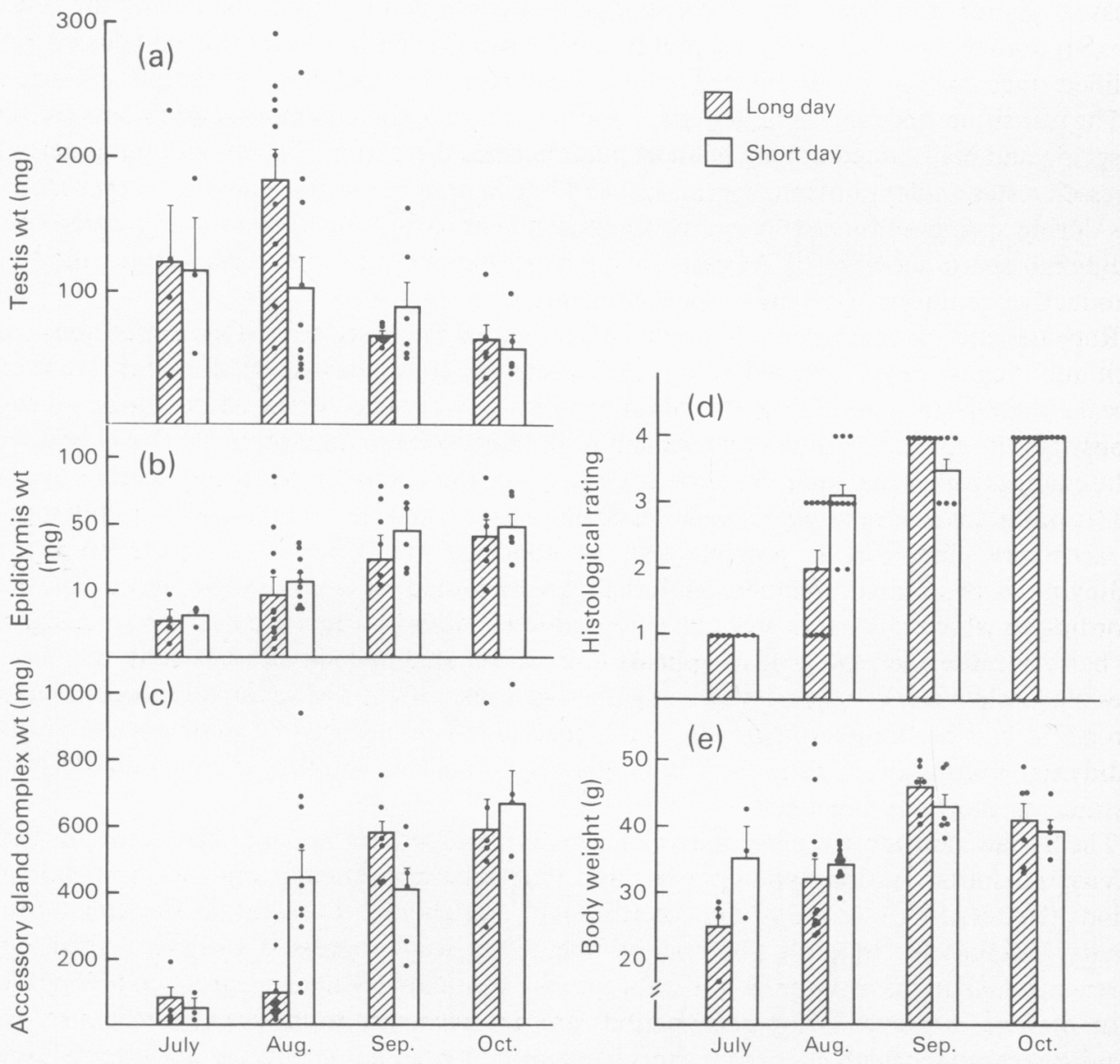

Text-fig. 3. Mean (+ s.e.m.) tissue and body weights and histological ratings of testes/epididymides of adult male pallid bats collected in April-May and kept in long-day or short-day photoperiods and autopsied between July and October. The values for individual animals are indicated. 
Histological rating of the testes and epididymides. Differences attributable to photoperiod were evident only during August, when the histological rating was greater for short- than for long-day bats $(P<0.01$; Text-fig. 3d). All short-day bats had epididymal spermatozoa whereas $55 \%(6 / 11)$ of long-day bats had epididymal spermatozoa; $50 \%(5 / 10)$ of the short-day bats and $9 \%(1 / 11)$ of the long-day bats had regressed testes in August. The histological rating was higher in SeptemberOctober than in July-August for animals in both photoperiods $(P<0.003)$. In July all bats had testes with primary and/or secondary spermatocytes and epididymides devoid of spermatozoa; all bats had regressed testes and epididymal spermatozoa between late September and late October.

Body weight. Photoperiod did not influence body weight during any month $(P>0.05$; Text-fig. $3 e)$. Bats were heavier in September or October than in August for short-day $(P<0.0001)$ and longday $(P<0.0001)$ bats.

\section{Discussion}

The seasonal cycle of pallid bats, based on specimens sampled soon after removal from the field, approximated the reproductive sequence described in other temperate-zone vespertilionid species (Gustafson, 1979). Spermatogenesis was restricted to the summer (July-September) and the accessory glands were heavy and the epididymides contained spermatozoa during the rest of the year (September-October and presumably until April-May); however, this conclusion must be qualified since animals were collected only between April and October and sample size was small.

The transition from spermatogenesis to sperm storage occurred amongst adult bats collected in the spring and maintained in long or short photoperiods thereafter. Bats in both photoperiods had regressed testes and epididymal spermatozoa in late September or late October. Exposure to short days during spring-summer accelerated the attainment of 'autumnal condition' (regressed testes, epididymal sperm storage) by August. By contrast, bats kept in long days showed the 'summer reproductive condition' (testicular spermatogenesis) in August.

Repeated measurements on individual bats indicated increased scrotal sac dimensions between April and August and decreased values in September. It appears likely, therefore, that all bats increase their testis size during the summer (Text-fig. 2). The regressed condition of testes at autopsy (in the autumn in long-day bats and in the summer and autumn in short-day bats) reflects cyclic changes rather than maintenance of a static condition between April and the time of autopsy.

Given the inverse relation between testicular activity and the weight of the epididymides and the accessory glands, it is possible that photoperiod exerts separate effects on the testes, epididymides or accessory glands. Mammals are classified as 'long-day' or 'short-day' breeders according to which daylength stimulates reproductive activity. Bats are difficult to categorize on this basis because spermatogenesis appears to be stimulated by long photoperiods, but copulation takes place when daylengths are short. If gametogenesis is identified as the relevant characteristic, then pallid bats are long-day animals; if the criterion of reproductive competence is presence of epididymal spermatozoa, large accessory glands or mating activity, then pallid bats may be classified as short-day breeders.

The Syrian hamster is representative of several photoperiodic rodents that maintain testicular activity indefinitely in long photoperiods and that undergo testicular regression in short photoperiods (Reiter, 1980). In pallid bats, neither long nor short days maintain functional testicular activity indefinitely; in each photoperiod the testes were regressed by late September. The decreasing daylengths of summer and autumn may stimulate testicular regression and epididymal sperm storage; however, short photoperiods are not necessary to induce this response. In most circumstances in the field, endogenous mechanisms may ensure that bats are in autumnal condition and able to inseminate females during the breeding season.

Testicular redevelopment is an important component of the photoperiodic response of long-day mammals (Zucker et al., 1980). In the golden hamster (Mesocricetus auratus: Reiter, 1980), white- 
footed mouse (Peromyscus leucopus: Johnston \& Zucker, 1980) or grasshopper mouse (Onychomys leucogaster: Frost \& Zucker, 1983) kept in short photoperiods, the testes manifest 'spontaneous' redevelopment after about 20-30 weeks. When pallid bats with regressed gonads (e.g. in October) are maintained in short days during the winter, the testes also undergo redevelopment after $\mathbf{3 0}$ weeks (Beasley, 1982).

It is necessary to reconcile photoperiodic responsiveness of pallid bats with failure of photoperiod to affect reproductive activity of pipistrelle bats (Racey, 1978). The experimental protocols followed were quite different in the two studies. The adult pipistrelles were held in long or short days between February and June whereas the pallid bats were treated between April and October. Photoperiodic cues might be expected to be less important at a time of year during which bats ordinarily hibernate (February-May) than when they are active daily (April-October). However, pallid bats have been netted during the winter (O'Farrell, Bradley \& Jones, 1967) and may be able to perceive the prevailing photoperiod at this time.

Increased temperature and food availability during the second half of hibernation stimulate spermatogenesis in the little brown bat (Myotis lucifugus: Gustafson, 1979). In pallid bats sampled between September and April, temperature is more important than photoperiod in affecting the reproductive apparatus. Captive bats maintained in a warm environment $\left(23 \pm 2^{\circ} \mathrm{C}\right)$ had large testes in April, whether kept in long or short photoperiods (Beasley, 1982). In contrast, bats kept in the cold $\left(11 \pm 3^{\circ} \mathrm{C}\right)$ had regressed testes in April as is true of bats collected from the field at this time (L. J. Beasley \& K. M. Pelz, unpublished observations). If warm temperatures during the winter enhance testicular development, thermal conditions during the summer could influence spermatogenesis as well.

Reproduction in pallid bats may be timed by an endogenous circannual clock that can be phaseadvanced by short photoperiods. Pallid bats exhibit robust circannual cycles of body weight ( $\mathbf{L}$. J. Beasley, K. M. Pelz \& I. Zucker, unpublished) and preliminary results indicate circannual cycles in scrotal size and plasma testosterone amongst bats kept under constant conditions. The effect of photoperiod during the summer probably reflects the action of a zeitgeber on an endogenous circannual rhythm. Similar phenomena have been described for sika deer (Goss, 1969).

This research was supported by Grant HD-02982 from the National Institute of Child Health and Human Development. L.J.B. was supported in part by a traineeship (T32-MH-15860). We thank Maxwell Redfearn, Division of Animal Resources, University of California, Berkeley, for laboratory facilities and K. M. Pelz, K. Fitzgerald, D. Frost, D. Whalen, M. Hamilton, B. Ries, N. Vermiere, A. Hunter and R. S. Henderson for technical assistance.

\section{References}

Beasley, L.J. (1982) Regulation of reproduction and body weight in pallid bats (Antrozous pallidus). Ph.D. thesis, University of California, Berkeley.

Frost, D. \& Zucker, I. (1983) Photoperiod and melatonin influence seasonal gonadal cycles in the grasshopper mouse (Onychomys leucogaster). J. Reprod. Fert. 69, 237-244.

Goss, R.J. (1969) Photoperiodic control of antler cycles in deer. I. Phase shift and frequency changes. J. exp. Zool. 170, 311-324.

Gustafson, A.W. (1979) Male reproductive patterns in bats. J. Reprod. Fert. 56, 317-331.

Herreid, C.F., II (1961) Notes on the pallid bat in Texas. SWest. Nat. 6, 13-20.

Johnston, P.G. \& Zucker, I. (1980) Photoperiodic regulation of the testes of adult white-footed mice (Peromyscus leucopus). Biol. Reprod. 23, 859-866.
Legan, S.J. \& Winans, S.S. (1981) The photoneuroendocrine control of seasonal breeding in the ewe. Gen. comp. Endocr. 45, 317-328.

Licht, P. (1984) Reptiles. In Marshall's Physiology of Reproduction, 4th edn, Vol. 1, ch. 3, pp. 206-282. Ed. G. E. Lamming. Churchill Livingstone, London.

Lincoln, G.A. (1981) Seasonal aspects of testicular function. In The Testis, pp. 255-302. Eds H. Burger \& D. de Kretser. Raven Press, New York.

O'Farrell, M.J., Bradley, W.G. \& Jones, G.W. (1967) Fall and winter bat activity in southern Nevada. SWest. Nat. 12, 163-171.

Racey, P.A. (1978) The effect of photoperiod on the initiation of spermatogenesis in pipistrelle bats, Pipistrellus pipistrellus. In Proc. 4th Int. Bat Res. Conf., pp. 255-258. Eds R. J. Olembo, J. B. Castelino \& 
F. A. Mutere. Kenya National Academy of Arts \& Sciences, Nairobi.

Racey, P.A. (1982) Ecology of bat reproduction. In Ecology of Bats, pp. 57-104. Ed. T. H. Kuntz. Plenum Press, New York.

Reiter, R.J. (1980) The pineal and its hormone in the control of reproduction in mammals. Endocr. Rev. 1, $109-131$.

Sadleir, R.M.F.S. (1969) The Ecology of Reproduction in Wild and Domestic Mammals. Methuen, London.
Wimsatt, W.A. (1969) Some interrelations of reproduction and hibernation in mammals. Symp. Soc. exp. Biol. 23, 511-549.

Zucker, I., Johnston, P.G. \& Frost, D. (1980) Comparative, physiological and biochronometric analyses of rodent seasonal reproductive cycles. Prog. Reprod. Biol. 5, 103-133.

Received 13 July 1983 